\title{
Risk, Preference, Capital Structure and Incentives
}

\author{
Zhongwei $\mathrm{Wu}^{1}$ \\ ${ }^{1}$ Seix Investment Advisors LLC, United States \\ Correspondence: Zhongwei Wu, Seix Investment Advisors LLC, 165 Broadway, Hastings on Hudson, NY \\ 10706, United States.
}

Received: April 25, 2018

Accepted: May 22, 2018

Online Published: June 5, 2018

doi:10.5539/ibr.v11n7p20

URL: https://doi.org/10.5539/ibr.v11n7p20

\begin{abstract}
Using the surplus theory of the firm, we examine capital and labor as inputs of a surplus generating firm, and study the capital structure of the firm. We derive two equilibrium models on: (a) the capital structure and ownership of the firm and (b) alternative incentive compensation structures. Within the framework of the firm as a cooperative surplus generating enterprise, we introduce the concepts of risk, preference and resource constraints, to provide a framework for analyzing more sophisticated methods of dividing the risks and rewards of the firm's surplus.
\end{abstract}

Keywords: firm, risk, preference, capital structure, incentives

\section{Theories of the Firm}

\subsection{Existing Theories}

The theory of the firm is usually associated with the Coase (1937) analysis of the firm, his contention that the firm uses command rather than the market mechanism, that the firm makes rather than buys intermediate products (the make-vs-buy decision). Since then, much of the literature on the subject has focused on explaining the firm by establishing the need for fiat/hierarchy, and the allocation of control rights.

However, the firm phenomenon is substantially more than a command structure. We broadly discern three categories of literature on the firm, which covers a wider range of literature than in Gibbons (2005).

The first group follows this Coasean tradition of viewing integration as representing a control structure. The crowning theories in this group are (a) the renting seeking theories of Williamson $(1971,1975,2000,2009)$, Alchian and Demsetz (1972), Klein et. al. (1978), and (b) the so-called the "property rights theory" of Hart et al. $(1986,1990,2008,2009,2011,2016)$ (GHM). We broadly call this group transaction cost economics (TCE). Much of the firm theory literature focuses solely on this aspect. This group has close siblings in the study of industrial organization.

The second group of literature analyzes the economics of the firm's investors and agents. This can be further divided into literature on the firm's capital structure, and literature on the firm's incentive structure. The landmark work of the first subgroup are of course Modigliani and Miller (1958) and Jensen and Meckling (1976). The latter is represented by a series of papers by Holmstrom $(1979,1991,2016)$ and Mirrlees (1976).

While the third group is less prominent than the prior two, it is more closely associated with the truism that capitalism is creative destruction. It focuses on the firm as an ever evolving enterprise that adapts to uncertain new conditions as they arise. It emphasizes the firm's role in handling the unknown. This tradition dates from Frank Knight (1921)'s emphasis of the entrepreneur, was further developed by Simon's (1951) insight and was alluded to by later theorists such as Williamson (1975).

The classification of the three broad categories of firm theories is illustrated in the Figure below. They are generally disparate and unrelated studies of the firm.

\subsection{The Surplus Theory}

In Wu (2018), Surplus, Contractibility and Theory of the Firm, a framework of firm as a legal construct of a joint property rights for surplus creation was laid out. We contend that viewing the firm in this framework provides a unifying structure to study the firm from all three perspectives. 


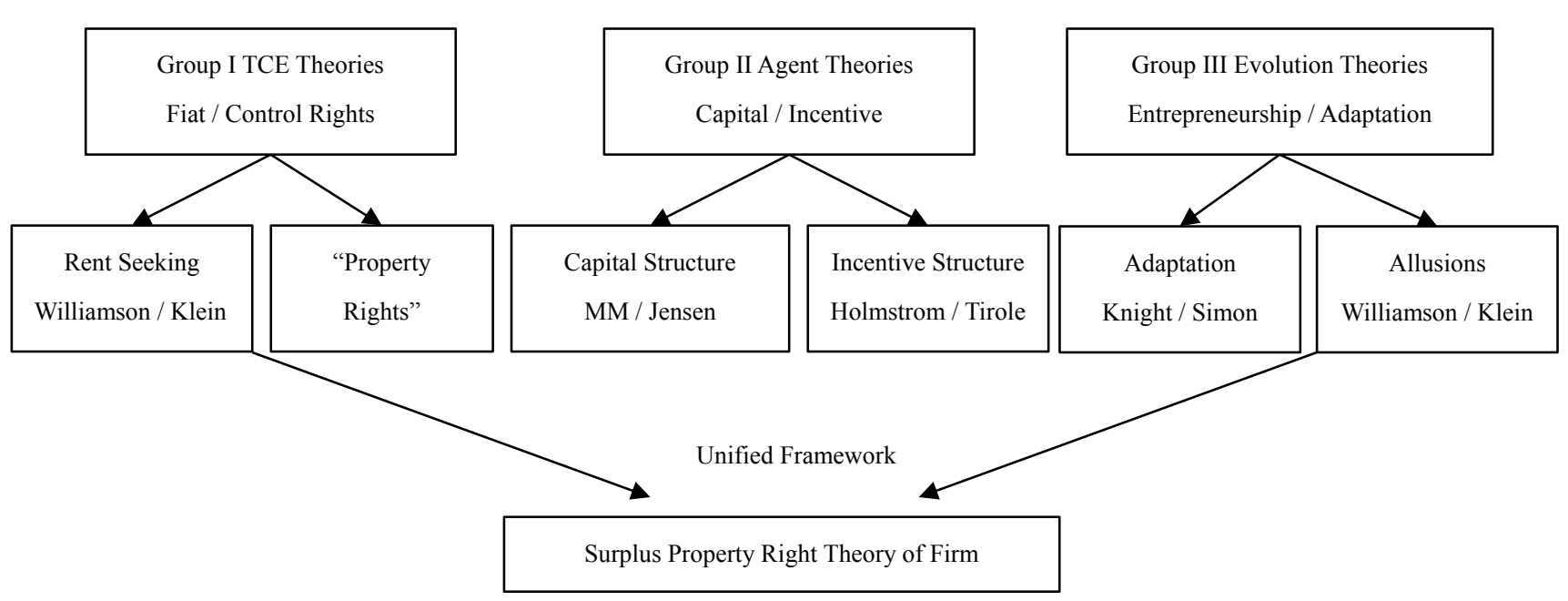

Figure 1. Surplus Property Right Theory of the Firm

The framework does away with some fundamentally inaccurate assumptions that plague the rent seeking or the "property rights" theories. While the rent-seeking theory assumes fiat (or governance structure) somehow removes ex-post opportunism, and the GHM theory assumes strategic behavior is only extant for ex-ante noncontractible specific investments, the surplus framework assumes each party will always act as her own agent in setting her non-contractible inputs to maximize her personal surplus (quasi-rent), with or without integration, exante or ex-post. The benefit of integration thus does not derive from creating a mutually exclusive control right (residual control right in Hart (2016)) that forces the other party to behave in a more benevolent way. Rather, the firm as a joint ownership of the surplus creates incentives for all parties to control their own respective strategic behavior, towards a better joint outcome. A crucial result is unlike in GHM and the rent seeking theories where a specific asset is a clutch of a reason for why integration is needed, specific assets become the result of the firm's surplus generation. No exogenous assumption is necessary - so long as surplus is created through cooperative activity and contracts are incomplete, a unified ownership of the surplus helps everybody. The other crucial point is that this represents a true property rights based theory of the firm, while GHM and TCE are really organizational behavioral theories. The original GHM theory leaves no room for joint ownership, and it took much development in the literature, and many additional assumptions to derive a more realistic ownership result. Gattai and Natale (2015) provided a good survey of this journey. In the Surplus theory, joint ownership is naturally derived.

The surplus framework was applied to create a formal model and derived all the major results of the first group of literature: firm existence, firm boundary and who should retain residual ownership and how much. However, its results are somewhat different from the rent seeking and the GHM theories: (a) unlike in the rent seeking theory, hierarchy is not efficient, (b) unlike in the GHM theory, ownerships does not imply control, (c) control rights should be bestowed upon the party whose decision making capability can generate the most surplus, not to the party with the more specific asset, and lastly, (d) firm purpose is independent from owners. This set of results obviously corresponds much better to real world intuitions - one should rise to the top of a company not because his skill is more specific, but because his decision is better, and everyone knows having a boss alone does not make an employee stop shirking.

In this paper, we will apply this theoretical framework to the questions covered by the second group of firm literature. Using the firm as a property rights construct for surplus creation, we analyze capital and labor as inputs. By introducing the concepts of risk and preference, we are able to answer the main questions of the firm's capital structure: (1) separation of ownership and control, (2) diverse ownership, transferability and limited liability of equity, (3) why firms use both debt and equity financing, (4) why debt cost should be less than the firm's return on capital. Furthermore, we will analyze ways of dividing up the risk and returns of the firm's surplus generation in ways other than equity and debt ownership. We will examine incentive payment contracts as an alternative to ownership, the principal-agent problem that arises from the separation of ownership and control, and derive that: (5) there is no perfect incentive structure, (6) the firm's operating and financing decisions cannot be fully separated. 


\section{Risk, Preference, and Capital Structure}

Once one sets the firm boundary so that specific inputs are internalized, a firm's external inputs should consist of only two kinds: (1) non-integrable inputs, such as labor, which broadly includes unskilled, skilled, managerial or entrepreneurial with varying degrees of specificity, and (2) non-specific inputs, such as fungible monetary capital. Labor cannot be integrated because the input can only be rented not owned, and it consists of a purposive entity's non-contractible behavior. Specific capital (possibly including machinery, plant and intellectual property) needs to be retained by the firm. Non-specific capital can be purchased with monetary capital. Therefore, one can assume the only form of external capital input is monetary. We can now change the notation of the two parties and two inputs to $\{K, L\}$, where $K$ denotes non-specific monetary capital, and $L$ denotes the entrepreneur/manager/labor, which is non-integrable. From prior work, non-specific input should not retain residual rights to surplus (or equity ownership). This seems to imply no third party investor should buy equity. If only the entrepreneur has surplus specificity, why do outside capital investors retain equity ownership and capital input is not limited to the form of debt only? ${ }^{1}$

An analogous situation is sharecropping. The entrepreneur of a firm is akin to the tenant, while the provider of monetary capital is like the landlord. Debt financing is equivalent to having the tenant pay fixed rent for the land, while equity financing is equivalent to the landlord paying the tenant a fixed wage. Traditional Marshallian analysis considers sharing of the crops inefficient because the tenant's marginal product of labor is higher than her marginal cost at equilibrium. Analysis by Stiglitz (1974) explains shared ownership by introducing risk preference. Under the assumption that the tenant is risk averse while the landlord is risk neutral, Stiglitz obtains sharing. However, if the tenant has the same risk preference as the landlord, the model predicts the tenant will take full ownership just like in the prior model.

In the real world, the situation is rather the opposite. There is generally no lender that will provide $100 \%$ of a firm's capital or the interest rate charged will make it uneconomical. The risk of capital loss makes the lender different from the landlord. If equity capital is needed, the entrepreneur is generally not capable of providing all of it, either.

Below, we enhance the model by introducing risk and preference explicitly, in a mean-variance framework. In this second model, each party's quasi-rent maximization becomes utility maximization, as a function of the party's preference for monetary return vs. risk. Our model will not make assumptions of risk neutrality by any party. Rather it will assume all parties are risk averse. We will derive that, under the assumption of similar risk preferences, there can be:

1. separation of ownership and control due to capital intensity

2. transferability and limited liability

3. mixed capital structure due to asymmetric payoff

A note on notation. Below, we will discuss four parties $k \in\{D, F, L, m\}, D$ for debt, $F$ for third party equity, $L$ for entrepreneur/manager, $m$ for the firm. We will denote, by $K_{k}$ the capital contribution of party $k$, by $d_{k}$ the ratio of the capital contributed by party $k$, by $Y_{k}$ the income of party $k$ in her best alternative, by $Y_{k}$ the income of party $k$ in the firm, by $S_{k}$ the surplus (quasi-rent) of party $k$, by $r_{k}$ the return of party $k$ or a particular variable $k$, by $\sigma_{k}$ the volatility of $r_{k}$, by $U$ the utility of party $k$, by $E$ [ ] the expectation value of a variable, by subscript $D$ a demand function, by subscript $S$ a supply function.

Furthermore, we denote by superscript * the idealized first best solution without constraints, by superscript ${ }^{\wedge}$ the actual optimal solution with constraints.

\footnotetext{
${ }^{1}$ The Modigliani and Miller Theorem (1958) assumes the firm's purpose is to maximize firm value or profit, and concludes that the firm's value is independent of how it is financed. Debt and equity are equivalent. Their theory assumes the absence of taxes, bankruptcy costs, agency costs, and asymmetric information. Their explanation of the capital structure is a tradeoff between tax savings of debt against bankruptcy costs from excessive leverage. Jensen and Meckling (1976) points out that the entrepreneur/manager can gamble with the firm at the expense of the debt investor, using the equivalence of firm equity as a call option on the firm asset. Unlike these two papers, our analysis puts strategic behavior by each agent at the center of assumptions, instead of maximization of firm value or minimization of agency costs. With asymmetric payoff and preference on capital intensity, we derive a mixed capital structure independent of taxes and bankruptcy costs.
} 


\subsection{Firm Model}

To model a typical firm with a capital structure, we assume there are two capital providers $D, F$, denoting debt and equity respectively, and one entrepreneur/manager/labor, denoted as party $L$. We assume there are two types of capital for debt and equity, with $K_{D}+K_{E}=K$ equal to the total capital. We denote $d_{D}=\frac{K_{D}}{K}, d_{E}=$ $\frac{K_{E}}{K}, d_{D}+d_{E}=1$. Only the entrepreneur $L$ has surplus specific inputs, with the contractible portion $i_{L}$ and the non-contractible portion $a_{L}$. The entrepreneur may also provide a portion of the equity $K_{L}=d_{L} K_{E}=$ $d_{L} d_{E} K, 0 \leq d_{L} \leq 1$ and retain a corresponding share of the firm profit $d_{L} S_{m}$, here $S_{m}$ is the firm's surplus. The equity party $F$ provides the rest of the equity $K_{F}=d_{F} K_{E}$, with $d_{L}+d_{F}=1$. $^{2}$

First, we analyze the ownership and capital structure decisions without risk or preference. The firm profit function is $S_{m}\left(i_{L}, a_{L}, K=K_{D}+K_{F}+K_{L}\right)=Y\left(i_{L}, a_{L}, K\right)-Y_{L}\left(i_{L}\right)-Y_{D}\left(K_{D}\right)$, and total surplus $S=S_{m}-C_{L}\left(a_{L}\right)$. Here we denote by $Y$ the joint income, by $Y_{L}$ the best alternative income to the entrepreneur (therefore, her wage), by $Y_{D}$ the best alternative income to the debt capital provider, and by $C_{L}$ the cost of the entrepreneur's non-contractible effort in $a_{L}$. Note we do not include an opportunity cost for the third party equity investor. The reason is we will use the firm profit and its volatility to match her risk preference in deriving the correct opportunity cost for her equity $r_{F}$ later. $^{3}$

We start by assuming unlimited liability, and the division of surplus into quasi-rents into the three parties is:

(i) the debt party $D$ 's income is only a fixed return $Y_{D}=r_{D} K_{D}$, with $r_{D}>1$ as a constant denoting the return of principal plus a fixed interest rate, and its opportunity cost is the same $Y_{D}=r_{D} K_{D}$ because of non-specificity, and there is no surplus to him $\Delta Y_{D}=Y_{D}-Y_{D}=0$,

(ii) the third-party equity $F$ 's income is a share of the firm profit $Y_{F}=d_{F} S_{m}$, and his surplus is $\Delta Y_{F}=Y_{F}-Y_{F}=d_{F} S_{m}-r_{F} K_{F}$,

(iii) the entrepreneur $L$ 's total income consists of (a) the wage $Y_{L}$, and (b) her share of the firm profit $d_{L} S_{m}$, over (c) her non-contractible cost $C_{L}$; so $Y_{L}=d_{L} S_{m}\left(i_{L}, a_{L}, K\right)+Y_{L}\left(i_{L}\right)-C_{L}\left(a_{L}\right)$, and her surplus is $\Delta Y_{L}=Y_{L}-Y_{L}=d_{L} S_{m}-C_{L}$.

The total income of all parties, $Y_{D}+Y_{F}+Y_{L}=Y\left(i_{L}, a_{L}, K\right)-C_{L}\left(a_{L}\right)$, as expected.

\subsection{No Risk Case}

To find the maximal surplus, we take the two step equilibrium process as in $\mathrm{Wu}$ (2018). First we assume the capital structure variables $d_{D}, d_{L}$ are given, and find the equilibrium inputs for each party. It consists of the simultaneous solution:

(a) the contractible input $i_{L}$ and amount of capital $K$ is set at an optimal level for all $\frac{\partial S}{\partial i_{L}}=0, \frac{\partial S}{\partial K}=0$,

(b) but the entrepreneur only optimizes her non-contractible input to maximize her own private quasi-rent

$$
\Delta Y_{L}=Y_{L}-Y_{L}, \frac{\partial \Delta Y_{L}}{\partial a_{L}}=d_{L} \frac{\partial Y}{\partial a_{L}}-\frac{\partial C_{L}}{\partial a_{L}}=0
$$

Next, we find the solutions of $d_{L}$ and $d_{D}$ that will maximize surplus.

${ }^{2}$ Equity investor voting has no effect in our model. The entrepreneur is assumed to have non-contractible inputs which the votes cannot change. Therefore, we assume voting only affects the contractible input, and the result remains the same with voting in our model.

${ }^{3}$ We differentiate the surplus net of all factor inputs including equity as $S_{f}$, which should be 0 . 
By Proposition 3 in $\mathrm{Wu}$ (2018), the entrepreneur should own all surplus $d_{L}=1$ because she has the only noncontractible specific input $a_{L}$. Only at $d_{L}=1, a_{L}$ is equal to the optimal level of $a_{L}$ that maximize total surplus, $\frac{\partial S}{\partial a_{L}}=\frac{\partial Y}{\partial a_{L}}-\frac{\partial C_{L}}{\partial a_{L}}=0$. As a result, the entrepreneur should own all of the equity, and get all of the surplus $\Delta Y_{L}=S$, there is no third-party equity holder $d_{F}=0$, and the debt holder earns her opportunity cost $\Delta Y_{D}=0$. This equilibrium solution is identical to the case where there is only one party $L$, and the equilibrium is under the conditions: $\frac{\partial S}{\partial i_{L}}=0, \frac{\partial Y}{\partial a_{L}}-\frac{\partial C_{L}}{\partial a_{L}}=0, \frac{\partial S}{\partial K}=0$. Because $\Delta Y_{D}=0$ irrespective of the debt level $d_{D}$, the capital structure question of $d_{D}$ cannot be derived from the model and is indeterminate, thus reproducing the Modigliani and Miller Theorem.

\subsection{Risk Case}

Next, we introduce risk by making the joint income $Y\left(i_{L}, a_{L}, K\right)$ a random variable, with its expected value the same as the function before. We denote the expected income as $E[Y]$, and the income volatility as $\sigma_{Y}$. Similarly, the firm and total surplus are now random variables with expected value $E\left[S_{m}\right], E[S]$, and volatility $\sigma_{S}=$ $\sigma_{S_{m}}=\sigma_{Y}$. Because $Y_{L}=d_{L} S_{m}+Y_{L}-C_{L}, \sigma_{Y_{L}} d_{L} \sigma_{S}$

We will derive the firm's surplus function as a "supply" of investment opportunity, and the parties' preference for risk and return as "demand" for investment opportunity. The interaction of the demand and supply then leads to the equilibrium solution.

To derive the firm as a supply of investment opportunity, we note the entrepreneur solves the following simultaneous equations:

(i) given any volatility $\sigma_{S}=\sigma_{Y}$, the contractible inputs: the amount of capital $K$ and the contractible input $i_{L}$ are set to optimize the expected surplus for all parties, $\frac{\partial E\left[S_{m}\right]}{\partial i_{L}} \quad \sigma_{S}=0, \frac{\partial E\left[S_{m}\right]}{\partial K} \quad \sigma_{S}=0$,

(ii) but, the entrepreneur only sets her non-contractible input to maximize her private quasi-rent for herself,

$$
\Delta Y_{L}=Y_{L}-Y_{L}, \frac{\partial E\left[\Delta Y_{L}\right]}{\partial a_{L}} \quad \sigma_{S}=\left(d|| L \frac{\partial E[Y]}{\partial a_{L}}-\frac{\partial C_{L}}{\partial a_{L}}\right) \quad \sigma_{S}=0
$$

Therefore, at any given volatility $\sigma_{\Delta Y_{L}} d_{L} \sigma_{S}$, the entrepreneur will maximize $E\left[\Delta Y_{L}\right]\left(\sigma_{\Delta Y_{L}}\right)$, by picking $i_{L}, a_{L}, K$. This determines the firm as a supply of investment $E\left[S_{m}\right]=E_{S}\left[S_{m}\right]\left(\sigma_{S}\right)$, where the expected firm surplus (profit) is a function of volatility. Here the subscript $S$ denotes the supply function.

We can further transform the variables by writing the firm's equity return as $r_{S}=S_{m} / K_{E}$, and $\sigma_{r}$ as the volatility of return $r_{S}$. Because $Y_{F}=d_{F} S_{m}, r_{F}=d_{F} S_{m} / d_{F} K_{E}=r_{S}$, and its volatility $\sigma_{F}=\sigma_{r}$. Similarly, because $\Delta Y_{L}=d_{L} S_{m}-C_{L}, r_{L}=\left(d_{L} S_{m}-C_{L}\right) / d_{L} K_{E} \cong r_{S}$, we assume $\sigma_{L}=\sigma_{r}$. Thus the supply of equity is approximately $E_{S}\left[r_{S}\right]\left(\sigma_{r}\right)$ for both the equity and entrepreneur. Note all of the returns $r_{k}, k \in\{S, F, L\}$ are random variables except for $r_{D}$, which is a constant number representing the stated return of debt.

To derive the "demand" for risky investments, we first assume each party $k$ have a utility function on investments as a function of its expected return and volatility $U_{k}\left(E\left[r_{k}\right], \sigma_{k}\right)$, where $E\left[r_{k}\right]$ is the expected return and $\sigma_{k}$ is the volatility of return $r_{k}$. We assume the normal properties of return preference and risk aversion $\frac{\partial U_{k}}{\partial E[r|\quad| k]>0, \frac{\partial U_{k}}{\partial \sigma_{k}}<0}$, and diminishing marginal utility $\frac{\partial^{2} U_{k}}{\partial E\left[r_{k}\right]^{2}}<0, \frac{\partial^{2} U_{k}}{\partial \sigma_{k}{ }^{2}}>0$. Therefore, for any 
indifferent utility level $U_{k}=u$, the implicit function theorem gives this party's required expected return as a function of volatility $E\left[r_{k}\right]=E_{D}\left[r_{k}\right]\left(\sigma_{k}\right)$. To see that, $d U_{k}=\frac{\partial U_{k}}{\partial E\left[r_{k}\right]} d E\left[r_{k}\right]+\frac{\partial U_{k}}{\partial \sigma_{k}} d \sigma_{k}=0 \rightarrow$ $\frac{\partial E\left[r_{k}\right]}{\partial \sigma_{k}}=\frac{\frac{-\partial U_{k}}{\partial \sigma_{k}} / \partial U_{k}}{\partial E[r|\quad| k]>0}$. This condition implies the required return for a given utility level is a monotonically increasing function of volatility. ${ }^{4}$ This is the party $k$ 's "demand" function for risky investments. The optimization task is thus to find the maximum $u$ where $E_{D}\left[r_{k}\right](\sigma) E_{S}[r|| S](\sigma)$, which implies $\partial \frac{E_{D}[r|k|}{\partial \sigma_{k}}=\partial \frac{E_{S}[r \mid S S]}{\partial \sigma_{r}}$ at the equilibrium. Here the subscript D denotes the demand function. To remove artificial asymmetry of the parties as in Stiglitz (1974), we assume the utility functions of the entrepreneur and the equity are the same, and the task is to explain third party ownership.

We note that utility maximization in this model is akin to the quasi-rent maximization in the prior model in $\mathrm{Wu}$ (2018). In each case, any given party will attempt to maximize her outcome in the cooperative endeavor over her best alternative. With no risk preference $\frac{\partial U_{k}}{\partial \sigma_{k}}=0$, and assuming $E[Y]$ represents the same income function as in the no risk case, this model will reproduces the prior model in section 2.2, because maximizing $U_{k}\left(E\left[r_{k}\right], \sigma_{k}\right)$ leads to the exact same decisions as maximizing $r_{k}$. While it is not the same as maximizing $\Delta Y_{k}$, it follows a similar deterministic procedure.

For the entrepreneur, her income $Y_{L}$ includes an additional term of the non-risky wage $Y_{L}$. However, this wage has no impact on her utility because she can get the wage elsewhere, regardless of her investment in the firm. The fact that her wage is exactly equal to her opportunity cost of her contractible input $i_{L}$ means the work and investment decisions can be bifurcated in the analysis. Therefore, it is assumed her utility does not depend on $Y_{L}$ or $Y_{L}$, but only on surplus $\Delta Y_{L}$.

\subsubsection{Ownership and Control}

At the equilibrium, both the entrepreneur and the equity equate their demands for investment to the firm's supply. Therefore, the third party equity will have the same ratio of marginal utility of expected return to margin disutility of volatility as the entrepreneur: ${ }^{5}$

$$
\begin{aligned}
& \text { With } \sigma_{F}=\sigma_{L}=\sigma_{r} \\
& E_{D}[r|\quad| F]\left(\sigma_{F}\right) E_{D}[r|\quad| L]\left(\sigma_{L}\right)=E_{S}\left[r_{S}\right]\left(\sigma_{r}\right), \partial \frac{E_{D}[r|\quad| F]}{\partial \sigma_{r}} \quad d_{F}=\partial \frac{E_{D}[r|| L]}{\partial \sigma_{r}} \quad d_{L}=\frac{\partial E_{S}\left[r_{S}\right]}{\partial \sigma_{r}}
\end{aligned}
$$

Thus, the marginal return must be the same for outside equity and the entrepreneur, at any given capital

\footnotetext{
${ }^{4}$ For example, under stronger assumptions such as the Capital Asset Pricing Model, $r_{k}=\beta_{k}\left(r_{M}-r_{f}\right)+r_{f}$, where $\beta_{k}=\operatorname{Corr}\left(r_{k}, r_{M}\right) \sigma_{k} / \sigma_{M}$, where $M$ denotes market, and $f$ denotes the risk free investment. This also has $\partial r_{k} / \partial \sigma_{k}=\operatorname{Corr}\left(r_{k}, r_{M}\right)\left(r_{M}-r_{f}\right) / \sigma_{M}>0$. However, our assumptions are much more generic.

${ }^{5}$ While the equity investor cannot contract with the entrepreneur the non-contractible input $a_{k}$, and may not even be able to fully observe that function $Y(a|| L)$, we assume the owner can get comfortable either (a) she has sufficient knowledge of the distribution of $Y$, or (b) her risk preference and utility function are of similar type with the entrepreneur, who does control the firm income $Y\left(a_{L}\right)$, and therefore at equilibrium this condition will hold.
} 
allocation $d_{F}$. This begs the question, why does the entrepreneur need third party equity? To see that, we introduce the concept of capital intensity. Let us use $K_{k}$ to denote the investment amount made by party $k$, and assume party $k$ 's utility function is sensitive to her capital investment $U_{k}\left(K_{k}, E\left[r_{k}\right], \sigma_{k}\right)$, where $\frac{\partial U_{k}}{\partial K_{k}} \leq 0$. This assumption captures the preference of the entrepreneur $L$ with limited capital, who exhibits disutility to capital intensity. However, capital markets have more depth and many individual's demand for the investment can be aggregated. Precisely because monetary capital is non-specific, the number of capital providers can be large. Of course, we implicitly assume the firm is productive enough that it generates a risk / return tradeoff that is accepted by the capital markets even with a low non-contractible $a_{L}$.

Assumption 1: at the point at which the entrepreneur's demand for investment $E_{D}[r|\quad| L]\left(\sigma_{L}\right)$ is roughly equal to that of the equity market $E_{D}\left[r_{F}\right]\left(\sigma_{F}\right)$, to the first order of approximation as in (1), $K_{F} \gg K_{L}$, or $d_{F} \gg d_{L}$

Proposition 1 Separation of Ownership and Control: Third party equity ownership is indicated when the entrepreneur's disutility for capital intensity is significant. If the entrepreneur shares with the equity the same risk preference (1), but has lower preference for capital intensity, then at the equilibrium outside equity owners will own the majority of the firm with $d_{L}<d_{F}$.

We can see that the separation of ownership and control thus naturally emerges from our model. While the entrepreneur has surplus specificity and hence requires control, the non-controlling capital provider can still own a portion of the residual rights of the firm. The cause is that the entrepreneur has capital intensity concerns while the capital market may not. The exact functional form of the utility function is not needed in deriving this result. The analysis holds if both the entrepreneur and the capital provider are risk averse, and they have the similar risk preferences at the equilibrium point.

At the equilibrium, the equity investor generates a return of $E_{D}\left[r_{F}\right]\left(\sigma_{F}\right)=E_{S}\left[r_{S}\right]\left(\sigma_{r}\right) \cdot E_{D}\left[r_{F}\right]\left(\sigma_{F}\right)$ is the risk/ return trade-off the investor's utility function dictates, taking into account all of her alternatives away from the firm. Therefore, $r_{S}$ must be equal to the opportunity cost of her capital at the given volatility. ${ }^{6}$ Thus, we get the result that $\Delta Y_{F}=Y_{F}-Y_{F}=d_{F} S_{m}-r_{F} K_{F}=d_{F} S_{m}-r_{F} d_{F} K_{E}=0$, so at equilibrium $r_{F}=$ $S_{m} / K_{E}$. Or in other words, we have derived what that opportunity cost $r_{F}\left(\sigma_{F}\right)$ of the third party equity, at a given risk $\sigma_{F}$, will be equal to the firm's equity return.

The ownership decision is set at the cross point between the entrepreneur's preferences and the capital market's preferences. If we assume the capital markets have no capital intensity aversion (as there can be as many investors as necessary), while the entrepreneur does, the ownership decision is essentially driven by the entrepreneur's preference.

One might question our assumption that the entrepreneur and the equity will share the same investment outcome where the entrepreneur puts up a pro-rata amount of capital $d_{L} K_{E}$. Isn't it often the case that the entrepreneur shares in the residual rights while third party equity provides all of the needed capital input $K_{E}$ ? We contend that the analysis is equivalent. If the entrepreneur is not putting up capital on the outset, the fact that third party investors are putting in capital $d_{F} K_{E}$ implies the firm already has an equity valuation of $K_{E}$. Thus the entrepreneur implicitly has equity value of $d_{L} K_{E}$, which in theory she can resell or hedge in the secondary market away from the firm. The decision that the entrepreneur sell $d_{F} K_{E}$ to third party investors (while still retaining a non-zero share $d_{L}$ is an expression of her risk/return preference not to put up cash in the amount of $d_{F} K_{E}$ in order to own the full value $K_{E}$, nor to sell the entire firm and set $d_{L}$ to zero. The outside equity's investment decision is also an expression of their risk/return preference to put up $d_{F} K_{E}$ in order to obtain $d_{F} S_{m}$. This describes exactly the scenario of a firm's initial public offering (IPO), or rounds of angel/venture investment into young firms. Alternatively, if a skilled manager joins an existing firm and is rewarded equity incentives without putting in capital, the situation is analogous. The fact that equity owners are diluting their residual rights implies that they view the manager has expanded the value of the firm so that their original

${ }^{6}$ For example, again, such a utility function can be the CAPM model under more restrictive assumptions. 
investment is now worth $d_{F} K_{E}^{\prime}$ of a more valuable firm, instead of the full equity of the original firm $K_{E}$. While the manager did not put up capital $d_{L} K_{E}^{\prime}$, her accepting $d_{L}$ of residual rights at the potential cost of a higher wage $Y_{L}$, implies an expression of her risk/return preference to make that investment. Neither the temporal sequence of events nor the capital outlay matters. In any circumstances, the entrepreneur/manager is expressing a risk/return investment preference.

Note, at the equilibrium, the utility of the entrepreneur still takes into account only a portion of the effect of her non-contractible input to the surplus, $Y_{L}\left(a_{L}\right)=d_{L} S_{m}+Y_{L}-C_{L}=d_{L}\left(Y\left(a_{L}\right)-Y_{D}\right)+$ $\left(1-d_{L}\right) Y_{L}-C_{L}\left(a_{L}\right)$. To the extent the entrepreneur's ownership is small, $d_{L} \ll 1$, her utility is heavily driven by her private income $\left(1-d_{L}\right) Y_{L}-C_{L}$, rather than the joint income $d_{L}\left(Y\left(a_{L}\right)-Y_{D}\right)$. As a result, she will manage $a_{L}$ in such a way that minimizes $C_{L}\left(a_{L}\right)$ without much regard for $Y\left(a_{L}\right)$. Both the entrepreneur and the equity are less satisfied than the case where the entrepreneur owns all the capital. In fact, the outside equity may indeed set her expectations with only contractible inputs and regard $a_{L}=0$. This constitutes one reason outside equity may prefer entrepreneur retention of partial residual ownership. However, due to limited entrepreneur capital, a tradeoff between $d_{L}$ and $a_{L}$ has to be made, and cooperation can still be better than the case where no third party equity is available.

Corollary 1.1 Non-optimization: At the equilibrium, the total surplus is not maximized.

\subsubsection{Capital Structure}

The non-specificity of equity capital means that the investments can be freely transferred to third parties. Thus the trading of firm equity in a secondary market also results. As the non-specificity of third party equity leads to the equity being freely transferable, it is easier to transfer the residual claim as a package of rights that does not come with recourse liabilities. ${ }^{7}$ Even more importantly, once equity ownership is diffuse from secondary market transfer, the debt investors' cost of pursuing equity owners beyond what they paid upfront may become prohibitive. Therefore, the modern debt investors choose instead to accept limited liability and charge a higher rate $r_{D}$ for it. Even if the entrepreneur is the only equity owner, it might still be very costly to assess her true financial resources and pursue recourse against her upon firm losses. That could be in effect the same as limited liability. This is assumed for the next step of our analysis. ${ }^{8}$

Proposition 2 Transferrability and Limited Liability: Third party equity ownership will be transferrable and diverse ownership indicates limited liability.

We assume $d_{L}$ is fixed, and derive the optimal debt level $d_{D} \cdot{ }^{9}$ The quasi-rents for the parties become bifurcated depending on whether the surplus is positive or negative:

(i) for any outcome in which $S_{m}=Y-Y_{L}-Y_{D} \geq 0, Y_{D}=r_{D} K_{D}, Y_{F}=d_{F} S_{m} \geq 0, Y_{L}=$ $d_{L} S_{m}+Y_{L}-C_{L}$

\footnotetext{
${ }^{7}$ There is a behavior economic description of human's preference where loss aversion is much stronger than satisfaction from gains. To the extent equity owners, who have information and control disadvantages, derive non-pecuniary benefit from limited liability, they may be willing to pay for it to the benefit of the entrepreneur. We will not explore this idea in detail.

${ }^{8}$ Jensen and Meckling (1976) talks about the invention of limited liability as a response to equity owner not being able to control the liability a firm incurs. We provide the other side of the explanation that the limited liability as a result of the high transaction cost of trying to collect in the event of firm failure.

${ }^{9}$ The fact that the debt party $D$ can incur a non-zero probability of loss also implies the entrepreneur will tend to set its non-contractible input $a_{L}$ in such a way as to increase the volatility of income $Y$. This is one reason the debt investor will not allow $d_{D}=1$ by charging a high $r_{D M}$. In our model, that behavior is already taken into account in the equilibrium decision made by the entrepreneur in setting $a_{L}$, and taken into account by debt investors in setting the $r_{D}\left(d_{D}\right)$. This includes bankruptcy cost.
} 
(ii) for any outcome in which $-K_{E} \leq S_{m}<0, Y_{D}=r_{D} D, Y_{F}=d_{F} S_{m}<0, Y_{L}=d_{L} S_{m}+$ $Y_{L}-C_{L}$

(iii) for any outcome in which $S_{m} \leftarrow K_{E}$, then limited liability causes equity to cap her loss at her original investment, $Y_{F}=-d_{F} K_{E}$, entrepreneur $Y_{L}=-d_{L} K_{E}+Y_{L}-C_{L}$, and now debt incurs a negative quasi-rent (loss), $Y_{D}=S_{m}+K_{E}+r_{D} K_{D}<r_{D} K_{D}=Y_{D}$ and $\Delta Y_{D}<0$.

We define the total firm value as $Y_{m}=Y-Y_{L}=S_{m}+Y_{D}$, which is independent of its capital decisions. We denote $r_{Y}=\left(Y-Y_{L}\right) / K$ as the return on capital of the firm, which is independent of the capital structure decision, and its volatility $\sigma_{Y}$.

With limited liability, there is a non-zero probability that debt will incur a scenario (iii) loss, $\Delta Y_{D}<0$. Now with non-zero probability of loss, debt investor's return is risky with volatility $\sigma_{D}$. Ceteris paribus, that probability increases as $K_{E}$ decreases and $K_{D}$ increase (a wider range for scenario (iii)), or equivalently $d_{D}=K_{D} / K \uparrow$. This implies $\sigma_{D}$ increases when $d_{D}$ increases, or $\frac{\partial \sigma_{D}}{\partial d_{D}}>0$. The expected return $E\left[Y_{D} / K_{D}\right]$ is monotonically increasing in the stated rate $r_{D}$. Given the debt investor utility function $\frac{\partial E\left[Y_{D} / K_{D}\right]}{\partial \sigma_{D}}>0$ and $r_{D}=Y_{D} / K_{D}$, we see that the required cost of debt goes up as leverage goes up $\frac{\partial E\left[r_{D}\right]}{\partial d_{D}}=\partial \frac{E[r|| D]}{\partial \sigma_{D}} \frac{\partial \sigma_{D}}{\partial d_{D}}>$ 0 .

For the entrepreneur, why would she want to incur debt? With non-zero debt $d_{D}>0$, her risk return is changed as follows: $r_{L} \cong r_{F}=r_{S}=\frac{s_{m}}{K_{E}}=\left(r_{Y}-d_{D} r_{D}\right) /\left(1-d_{D}\right)$. Assuming $d_{L}$ is fixed, optimizing her return relative to debt $\frac{\partial r_{Y}}{\partial d_{D}}=0$ :

$$
\partial \frac{E[r|\quad| L]}{\partial d_{D}}=\frac{E\left[r_{Y}\right]-r_{D}}{\left(1-d_{D}\right)^{2}}-\frac{\partial r_{D}}{\partial d_{D}} \frac{d_{D}}{1-d_{D}}
$$

We also have $\sigma_{L} \cong \sigma_{Y} /\left(1-d_{D}\right)$, and $\frac{\partial \sigma_{L}}{\partial d_{D}}=\frac{\sigma_{Y}}{\left(1-d_{D}\right)^{2}}$

Like the ownership decision, the entrepreneur will find the optimal $d_{D}$, by maximizing her utility $U_{L}\left(r_{L}, \sigma_{L}\right)$, which results in the condition $\partial \frac{E_{D}[r|| L]}{\partial \sigma_{L}}=\partial \frac{\frac{E_{D}[r|| L]}{\partial d_{D}} / \partial \sigma_{L}}{\partial d_{D}}$.

Let us examine the conditions at the boundaries. First, we start from no debt, $d_{D}=0, r_{D}=1+r_{f}$, the risk free rate. If $E[r|| Y]>r_{D}$, and one assumes debt cost and volatility are not very sensitive at low leverage, $\frac{\partial r_{D}}{\partial d_{D}} \cong 0, \frac{\partial \sigma_{D}}{\partial d_{D}} \cong 0 \quad, \quad$ then $\quad\left(E[r|| Y]-r_{D}\right) /\left(1-d_{D}\right) \cong\left(E[r|\quad| Y]-r_{D}\right)>0 \cong \frac{\partial r_{D}}{\partial d_{D}} d_{D}$, therefore $\partial \frac{E[r|| L]}{\partial d_{D}}>0$ from (2). This means: because the entrepreneur gets an increasing return at very low leverage while the volatility is insensitive to increasing leverage, the entrepreneur chooses to increase leverage $d_{D}>0$. 
Second, at infinite leverage, $d_{D}=1$, the volatility increase approaches infinity because $\frac{\partial \sigma_{L}}{\partial d_{D}}=\frac{\sigma_{r}}{\left(1-d_{D}\right)^{2}}$. To calculate the return $r_{L}$, let us examine the return on debt at full debt financing $r_{D M}=\lim _{d_{D} \rightarrow 1} r_{D}$ vs the return on equity at full equity financing $r_{E M}=\lim _{d_{D} \rightarrow 0} r_{Y}$. With $d_{L}$ fixed, we see that at $d_{D}=1, K_{D}=$ $K, K_{E}=0$, scenario (iii) above would indicate anytime $S_{m}<0, Y_{D}=S_{m}+K_{E}+r_{D M} K=Y-Y_{L}<$ $r_{D M} K$ the opportunity cost, while anytime $S_{m} \geq 0, Y_{D}=r_{D M} K$. This shows the debt investor only shares in the loss of the firm, but not the gain, he must ask for a higher return than the firm itself. Therefore, $r_{Y}=$ $\left(Y-Y_{L}\right) / K \leq r_{D M}$. On the other hand, if there is no debt, $d_{D}=0, K_{E}=K$, the equity return $r_{E M}=$ $\left(Y-Y_{L}\right) / K=r_{Y}$ equals the firm distribution of $r_{Y}=\left(Y-Y_{L}\right) / K$. Assuming party $D$ and $F$ have similar risk/return preferences, given the two limiting cases have the same capital intensity of $K$, it must be the case that $r_{D M}>E\left[r_{E M}\right]=E\left[r_{Y}\right]$.

So we conclude at $d_{D}=1, E\left[r_{Y}\right]-r_{D}<0$, the first term of (2) has negative expectation values. The second term in (2) is positive given $\frac{\partial r_{D}}{\partial d_{D}}>0$, thus $\frac{\partial E\left[r_{L}\right]}{\partial d_{D}}<0$ in (2). Or expressed in words:

Proposition 3 Capital Structure Decision: Under limited liability, the debt investor has asymmetric return profile vs. the equity investor. The entrepreneur maximizes her utility in the capital structure decision, taking into account the debt market's required return for assuming asymmetric risk. If one assumes the debt investor has the same risk preference as the equity investor, the stated debt cost at infinite leverage will be higher than the firm's expected return, and it becomes uneconomic for the firm to incur debt. Therefore the equilibrium capital structure will not consist only of debt $d_{D}<1$.

At equilibrium $d_{D}$, it must be that

$$
\frac{\partial U_{L}}{\partial E\left[r_{L}\right]} \frac{\partial E\left[r_{L}\right]}{\partial d_{D}}+\frac{\partial U_{L}}{\partial \sigma_{L}} \frac{\partial \sigma_{L}}{\partial d_{D}}=0
$$

Since $\frac{\partial U_{L}}{\partial \sigma_{L}}<0 \frac{\partial \sigma_{L}}{\partial d_{D}}>0$, we have $\frac{\partial U_{L}}{\partial E\left[r_{L}\right]} \frac{\partial E\left[r_{L}\right]}{\partial d_{D}}>0$. With $\frac{\partial U_{L}}{\partial E\left[r_{L}\right]}>0$, it must be $\frac{\partial E\left[r_{L}\right]}{\partial d_{D}}>0$. From (2), that implies $E\left[r_{Y}\right]-r_{D}>\frac{\partial r_{D}}{\partial d_{D}}\left(1-d_{D}\right) d_{D}>0$ because each term on the right is greater than zero. This conforms to our intuition:

Corollary 3.1 Firm Borrowing Cost: At the equilibrium capital structure, the firm's borrowing cost $r_{D}$ shall be less than the firm's return on capital, $r_{D}<E\left[r_{Y}\right] \quad d_{D}$.

How does this model prediction compare with results of prior literature? Modigliani and Miller (1958) concludes that the capital structure decision has no impact on firm value. Our model gives the same result that the total firm value $V$ or the return on capital $r_{Y}=\left(Y-Y_{L}\right) / K$ are not impacted by the level of debt $d_{D}$. However, we conclude differently that there is an equilibrium debt financing level. Stiglitz (1974) concludes that under landlord risk neutrality, sharecropping can be efficient. We instead derive under same risk aversion by labor and capital owner, financing cannot be all in debt, and capital intensity aversion can lead to outside equity as well. Jensen and Meckling (1976) sets the optimal capital structure where the marginal agency cost of debt and the marginal agency cost of equity cancels each other out, assuming the entrepreneur's capital is fixed. What does our model predict? 
Let us change the assumption that it is total entrepreneur capital rather than her participation level $d_{L}$ that is fixed, and determine the optimal capital structure. This means $K_{L}=d_{L}\left(1-d_{D}\right) K$ is constant, which results in $\frac{\partial d_{L}}{\partial d_{D}}=\frac{d_{L}}{1-d_{D}}$, and therefore $\frac{\partial E\left[r_{Y}\right]}{\partial d_{D}}=\frac{\partial E\left[r_{Y}\right]}{\partial a_{L}} \frac{\partial a_{L}}{\partial d_{L}} \frac{d_{L}}{1-d_{D}}$. If we make the further assumption that the marginal utility cost in volatility is negligible:

Assumption $2: \frac{\partial \sigma_{L}}{\partial d_{D}} \cong 0$ at the equilibrium capital structure, then (3) implies $\frac{\partial E\left[r_{L}\right]}{\partial d_{D}}=0$,

From $r_{L}=\left(r_{Y}-d_{D} r_{D}\right) /\left(1-d_{D}\right)$,

$\partial \frac{E[r|| L]}{\partial d_{D}} \quad d_{D}=0 \rightarrow \frac{E\left[r_{Y}\right]}{1-d_{D}}+\partial \frac{E[r|| Y]}{\partial d_{D}}=\frac{r_{D}}{1-d_{D}}+\frac{\partial r_{D}}{\partial d_{D}} d_{D} \quad d_{D}$, or

$$
E[r|| Y]+d_{L} \partial \frac{E[r|| Y]}{\partial a_{L}} \frac{\partial a_{L}}{\partial d_{L}}=r_{D}+\frac{\partial r_{D}}{\partial d_{D}} d_{D}\left(1-d_{D}\right)
$$

The term on the left is the marginal cost of equity. In addition to losing the return on capital of $E[r|| Y]$, the second term reveals the fact that $d_{L}$ decreases and the entrepreneur's consequent strategic behavior will also be partially born by herself. The first term on the right is the marginal cost of debt. In addition to the debt interest rate, there is also an increase in the interest rate due to increased leverage. Compared to (2), the different assumption of fixed entrepreneur capital causes there to be an extra second term on the left, which is the agency cost of using more outside equity. The agency cost of debt, on the other hand, is incorporated into the second term on the right as the increase in debt cost due to leverage. One notices that there are two reasons the marginal agency cost of debt is different from the marginal agency cost of equity. The factor of $d_{L}<1$ in the equity agency cost means equity owners bear part of the entrepreneur's non-contractible behavior, and there is a difference between the return on capital $r_{Y}$, and the total impact of debt cost, $r_{D}$ plus the interest rate increase. Note the change in interest rate from leverage comes from volatility increases in addition to agency behavior. Even if one ignores volatility changes, the marginal increase in capital does not result in agency cost minimization as in Jensen and Meckling (1976), because risk preference of debt investors now impacts return opportunity to the entrepreneur inherently. Therefore, instead of minimizing agency costs as in Jensen and Meckling, the party in control is maximizing her quasi-rent. Agency cost is also very different from contracting costs envisioned by Coase (1937).

Corollary 3.2 Non-Minimization of Agency Costs: At the equilibrium, agency cost in the firm is not minimized. When the entrepreneur's volatility sensitivity is negligible with her capital fixed, the marginal cost of outside equity equals the marginal cost of debt. However, just like the firm does not maximize profits by Corollary 1.1, the firm does not minimize agency costs, which depends on both conditions of firm profit maximization as well as separability of the firm's financing and operational activities.

In this section, we analyzed each of the equilibrium ownership $d_{L}$ and equilibrium capital structure $d_{D}$ in isolation, but holding other variables constant. In actuality, the equilibrium solution would require the simultaneous decision of 5 variables $i_{L}, a_{L}, K, d_{L}, d_{D}$. The difference is that $i_{L}, K$ are contracted to maximize total surplus, while $d_{L}, a_{L}$ are set as a pair by the entrepreneur's individual utility maximization, in addition to $d_{D}$. However, we note that if the effect of $a_{L}$ is ignored, the variables $i_{L}, K$ can be determined independent of the other variables $d_{L}, d_{D}$, when one is optimizing the total firm value $V$ independent of capital structure. That is because, $i_{L}$ is contractible even if it is surplus specific, and $K$ is non-specific. These variables are determined to be at the optimal level for the firm even if the entrepreneur changes the other variables to maximize her own utility. That means, the firm's operating decisions $\left(i_{L}, K\right)$ are independent of its financing decisions $\left(d_{L}, d_{D}\right.$. Thus, Fisher's second separation theorem is reproduced. ${ }^{10}$

\footnotetext{
${ }^{10} \mathrm{We}$ do not discuss the investment decision, as the model has subsumed it into the operating decision.
} 
However, the more complete model has a non-contractible production input $a_{L}$, and that the investment decision $d_{L}$ does impact the production decision $a_{L}$ and vice versa. Therefore:

Proposition 4 Non-Separation of Operating and Financing Decisions: under assumption of non-contractible specific labor input, the firm's operating decision and its financing decision cannot be fully separated, and the financing decision $d_{L}$ will influence its non-contractible operating decision $a_{L}$.

What we have accomplished in this section? We have thus built a model that: (a) incorporates risk into each party's preference, (b) puts all parties on equal footing in the risk/return framework, (c) generates an equilibrium solution for all three parties, and (d) set boundary conditions to derive the firm's financing decisions: third party equity ownership, limited liability, and a mixed capital structure, where $d_{L}<1 \wedge d_{D}<1$.

As a final note, all of the results in this section relies on the approximation the private cost of the entrepreneur is negligible $a_{L} \cong 0$, therefore

$$
r_{L}=\left(d_{L} S_{m}-C_{L}\right) / d_{L} K_{E} \cong r_{S}
$$

We see the entrepreneur has an incentive to (a) lower $C_{L}$ or in other words, reduce effort or increase non-pecuniary gains since $C_{L}$ is not contractible, (b) assuming the same risk preference between the entrepreneur and equity, $r_{L}\left(\sigma_{L}\right)=r_{F}\left(\sigma_{F}\right)$, decrease $d_{L}$, or failing that, decrease $K_{E}$, and (c) to the extent information on the volatility of the firm $\sigma_{r}$ is not fully observable to debt, increase $\sigma_{r}$ by altering $a_{L}$, and thereby increasing $\sigma_{D}$, i.e., making operating decisions that increase the firm's volatility due to its limited liability.

\section{Asymmetric Information and Incentive Structure}

The entrepreneur's aversion to capital intensity causes her to sell down her residual rights ownership $d_{L}$, but there is an associated cost in the reduction of her non-contractible behavior $a_{L}$. However, the firm can still design mechanisms to improve her non-contractible behavior through reward structures not tied to residual rights ownership. We noted previously that hierarchy is not optimal and one can improve upon it. The choices available are more than simple fiat, or equity ownership. The study of these incentive structures relates closely to the principal-agent literature, and is the focus of this section. We note that there is already a rich body of research on various incentive issues in the principal-agent problem (e.g., Holmstrom 1979, 1991, 2016), revolving around informative-ness. Our investigation here is to illustrate how incentive structure can be similarly handled in our theoretical framework.

\subsection{Incentive Compensation without Risk}

We noted before the input owner $k$ 's non-contractible behavior $a_{k}$ is set at a level that maximizes her quasi-rent. Assuming $a_{k}$ and $C_{k}$ are neither contractible nor observable, then one can set an incentive scheme away from residual rights ownership to correct for such strategic behavior. Assume party $k$ 's income is now $Y_{k}=d_{k} S_{m}-$ $Y_{k}-C_{k}+I_{k}$, with an additional incentive payment of $I_{k}(Y)$ which depends on the joint income $Y$. To move party $k$ 's non-contractible input from $a_{k}$ to $a_{k}$, the incentive payment should have the following properties:

(i) $\frac{\partial I_{k}}{\partial a_{k}}=\frac{\partial I_{k}}{\partial Y} \frac{\partial Y}{\partial a_{k}} \quad a_{k}>0$, therefore $\frac{\partial Y_{k}}{\partial a_{k}}=\left(d_{k} \frac{\partial Y}{\partial a_{k}}-\frac{\partial C_{k}}{\partial a_{k}}+\frac{\partial I_{k}}{\partial a_{k}}\right) \quad a_{k}>0$, and for all $a_{k}>a_{k}$, till

(ii) $\frac{\partial I_{k}}{\partial Y} \rightarrow 1-d_{k} \quad a_{k} \quad, \quad$ therefore $\frac{\partial I_{k}}{\partial a_{k}} \quad a_{k}=\frac{\partial I_{k}}{\partial Y} \frac{\partial Y}{\partial a_{k}} \quad a_{k}=\left(1-d_{k}\right) \frac{\partial Y}{\partial a_{k}} \quad a_{k} \quad$, and $\frac{\partial Y_{k}}{\partial a_{k}}=$ $\left(d_{k} \frac{\partial Y}{\partial a_{k}}-\frac{\partial C_{k}}{\partial a_{k}}+\frac{\partial I_{k}}{\partial a_{k}}\right) \quad a_{k} \rightarrow \frac{\partial Y}{\partial a_{k}}-\frac{\partial C_{k}}{\partial a_{k}} \quad a_{k}=0$

This will reproduce the "ideal" non-contractible behavior $a_{k}$, in the case of one party in the cooperative activity. This constitutes one solution of the principal-agent problem, where the principal pays out-of-pocket for the optimal behavior of the agent. In the situation where only one entrepreneur $L$ has the only non-contractible input, the equity owners $F$ can structure $L$ 's wages to have this additional incentive element. 
However, if there are multiple parties with non-contractible inputs, the firm surplus is reduced by the incentive payments $S_{f}=Y-\sum I_{k}-\sum Y_{k}$. Thus, $\frac{\partial Y_{k}}{\partial a_{k}}=d_{k} \frac{\partial Y}{\partial a_{k}}+\left(1-d_{k}\right) \frac{\partial I_{k}}{\partial a_{k}}-\frac{\partial C_{k}}{\partial a_{k}}$. For any $a_{k}$ to approach $a_{k}$, $\frac{\partial I_{k}}{\partial Y} \quad a_{k}=1$ is necessary. However, $\sum \frac{\partial I_{k}}{\partial Y} \leq 1$ is a necessary boundary condition, therefore the incentive structure cannot fully restore the "ideal" equilibrium.

Proposition 5 No Perfect Incentive Schemes: With more than one party with non-contractible behavior, there is no incentive scheme that will restore the "ideal" equilibrium and reduce agency cost to zero.

\subsection{Incentive Compensation with Risk}

In practice, the non-contractible behavior is not only non-observable, but its effect on the actual joint income is also uncertain, depending on factors outside all parties' control. Therefore, we recast the joint income as a random variable again. It depends on the agent's behavior but is not deterministic. In this section, we simplify the analysis by:

(i) There is only one principal (e.g., the equity party $F$ ), and one agent (e.g, the entrepreneur $L$ );

(ii) Only the agent has non-contractible behavior; and we remove subscripts for each party, and denote noncontractible behavior only by $a$, private cost by $C$, the entrepreneur sharing in income now a variable function of income $s(Y)$, the contractible input $i$ is assumed constant, and we ignore its effect on income $Y$;

(iii) $Y$ is no longer a function of $a$, instead, the cumulative distribution for the income is characterized by $F(Y) \quad a$, with its density function $f(Y) \quad a$ not necessarily continuous;

(iv) For each variable, we use subscript to denote its derivative to another variable: $s_{Y}=\frac{\partial s}{\partial Y}, f_{a}=\frac{\partial f}{\partial a}$, and

$$
f_{a a}=\frac{\partial^{2} f}{\partial a^{2}}
$$

Note the function $s(Y)$ replaces the prior constant residual sharing of $d_{L}$, which is reproduced if $\frac{\partial s}{\partial Y}=d_{L}$.

We can make some general assumptions that do not limit the generality of the analysis:

(i) $0 \leq s(Y) \leq 1, \int f \quad a=1$;

(ii) Input $a$ is non-trivially accretive to the income, or $F_{a} \leq 0$, where some $F_{a}<0$; and diminishing returns to effort: $F_{a a} \geq 0$;

(iii) $f_{a}(-\infty)=f_{a}(\infty)=0$.

Assuming each party optimizes her expected income/quasi-rent, and the principal has an additional tool of the incentive scheme $s(Y)$ at her disposal. Therefore, the equilibrium is now characterized by:

(i) the agent sets her non-contractible input so that her expected income is maximized: $\frac{\partial E\left[\Delta Y_{L}\right]}{\partial a}=0$, where

$$
\begin{aligned}
& E\left[\Delta Y_{L}, a\right]=\int_{Y} s Y f(Y, a) d Y-C(a), \text { and } a \text { is set such that } g(a)=\frac{\partial\left(\int_{Y} s Y f(Y, a)-c\right)}{\partial a}= \\
& \int s Y f_{a}-C_{a}=0_{a} \text {, and }
\end{aligned}
$$

(ii) the principal sets up the sharing function $s(Y)$ to maximize her expected income: $E\left[Y_{F}\right]=$ $\int(1-s) Y f d Y=\int h d Y$

The goal is to find the optimal incentive scheme $s(Y)$ for (ii) given the constraint in (i). The result is different 
from the first best solution if the principal and agent is the same: $\frac{\partial E[Y-C]}{\partial a}=\int Y f_{a} d Y-C_{a}=0$.

\subsection{Monitoring}

The principal in this case, still has the income incentive option as discussed before. However, she can also exert efforts $m_{k}$ in monitoring and rewarding the agent's non-contractible behavior directly. Such monitoring activity incurs a cost $C_{k}\left(m_{k}\right)$. We assume the observed variable $A$ in addition to $Y$ is intricately linked to the efforts $a$, so the reward function is $s(Y, A)$, where $A$ is a function of unobservable non-contractible input $a_{k}$. The agent's quasi-rent in this case is $E\left[\Delta Y_{L}\right]=\int s(Y, A(a)) Y f(Y, a) d Y-C(a)$, and

The principal's income is $E\left[Y_{F}\right]=\int(1-s(Y, A)) Y f(Y, a) d Y-C(m)$

\subsection{Summary}

We have created a framework for studying incentive structures that can lead parties to improve their noncontractible behavior in the cooperative activity. Note none of the incentive structures require fiat to function. Investment in monitoring can create better alignment of rewards and efforts. However, it does not require authority, but instead is a rational choice by both the principal and the agent for mutual gains. The questions of incentives and control are thus separate. From Wu (2018), we already see the firm serves as a unified property right of surplus ownership which removes haggling. Thus, the separation of hierarchy from the question of incentive is complete.

Proposition 6 Separation of Incentive Structures From Hierarchy: Incentive structures do not rely on hierarchy.

We also note that the assumption of a firm is not necessary in the incentive structures we study. It applies equally well to a relationship between an employer and employee, which is by our definition non-integrated. The study of integration, incentive structures, and the study of control rights can go down separate and parallel paths.

\section{Conclusion}

Our studies present a deviation from Coase's original thesis of the firm as a command mechanism. We have shown that it is not the fundamental feature that distinguishes a firm from other organizations. While the study of hierarchical organization structures is a fruitful endeavor in itself, it has to focus on how the allocation of authority improves joint outcome, rather than how it reduces "cost."

In this paper, we build on $\mathrm{Wu}(2018)$ and further analyze the firm as a surplus creation mechanism from its inputs of capital and labor. By incorporating risk/uncertainty, preference and resource constraints, a rich theory of capital structure and incentive compensation can be developed as an integral part of the theory of the firm.

Our study differs from the prior capital structure work significantly:

(i) it uses an integral framework of the firm as a cooperative surplus creation mechanism with its own property rights, however,

(ii) instead of studying the firm as a purposive entity itself, each party continues to act to maximize her own interest

Therefore, it derives useful theorems of the capital structure theory: separation of ownership and control, third party equity ownership, and a non-zero equilibrium debt level. These results differ from Modigliani and Miller (1958). Agency cost is not minimized, which differ from the Jensen and Meckling (1976). Furthermore, we have developed a theory of the firm as incentives in a surplus creation endeavor, rather than a hierarchy. We see that the firm actually does not really maximize profits, and ownership/financing decisions impact operations. The richness of this method is demonstrated in unifying the strategic behavior discussion from TCE, and the capital structure and principal-agent incentive literature in the same framework. From this, we further derive that there is no perfect incentive structure and that incentives do not necessitate hierarchy.

\section{References}

Alchian, A., \& Demsetz, H. (1972). Production, Information Costs, and Economic Organization. American Economic Review, 62(5), 777-795.

Coase, R. H. (1937). The Nature of the Firm. Economica, 4(16), 386-405. https://doi.org/10.1111/j.14680335.1937.tb00002.x 
Gattai, V., \& Natale, P. (2015). A New Cinderella Story: Joint Ventures and the Property Rights Theory of the Firm. Journal of Economic Surveys.

Gibbons, R. (2005). Four Formal (izable) Theories of the Firm? Journal of Economic Behavior and Organization, 58(2005), 200-245. https://doi.org/10.1016/j.jebo.2004.09.010

Grossman, S. J., \& Hart, O. (1986). The Costs and Benefits of Ownership: A Theory of Vertical and Lateral Integration. Journal of Political Economy, 94(4), 691-719. https://doi.org/10.1086/261404

Hart, O. (2008). Coase Lecture: Reference Points and the Theory of the Firm. Economica, 75, 404-411. https://doi.org/10.1111/j.1468-0335.2007.00659.x

Hart, O. (2009). Hold-up, Asset Ownership, and Reference Points. Quarterly Journal of Economics, 124, 267300. https://doi.org/10.1162/qjec.2009.124.1.267

Hart, O. (2011). Thinking about the Firm: A Review of Daniel Spulber's The Theory of the Firm. Journal of Economic Literature, 49(1), 101-113. https://doi.org/10.1257/jel.49.1.101

Hart, O. (2016). Nobel Prize Lecture.

Hart, O., \& Moore, J. (1990). Property Rights and the Nature of the Firm. Journal of Political Economy, 98: 1119-1158. https://doi.org/10.1086/261729

Holmstrom, B. \& Milgrom, P. (1991). Multitask Principal-Agent Analyses: Incentive Contracts, Asset Ownership, and Job Design. Journal of Law, Economics, and Organization, 7, 24-52. https://doi.org/10.1093/jleo/7.special_issue.24

Holmstrom, B. (2016). Nobel Prize Lecture.

Homstrom, B. (1979). Moral Hazard and Observability. The Bell Journal of Economics, 10 (1), 74-91. https://doi.org/10.2307/3003320

Jensen, M. C., \& Meckling. W. H. (1976). Theory of the Firm: Managerial Behavior, Agency Costs and Ownership Structure. Journal of Financial Economics, 3(4), 305-360. https://doi.org/10.1016/0304-405X(76)90026-X

Klein, B., Crawford, G. R., \& Alchian. A. (1978). Vertical Integration, Appropriable Rents, and The Competitive Contracting Process. Journal of Law and Economics, 21(2), 297-326. https://doi.org/10.1086/466922

Knight, F. (1921). Risk, Uncertainty and Profit. Boston: Hart, Schaffner \& Marx.

Mirrlees, J. (1976). The Optimal Structure of Incentives and Authority Within an Organization.” The Bell Journal of Economics. 7(1), 105-131. https://doi.org/10.2307/3003192

Modigliani, F., \& Miller, M. H. (1958). The Cost of Capital, Corporation Finance and the Theory of Investment. American Economic Review, 48(3), 261-297.

Simon, H. (1951). A Formal Theory of the Employment Relationship. Econometrica, 19, 293-305. https://doi.org/10.2307/1906815

Stiglitz, J. (1974). Incentives and Risk Sharing in Sharecropping. Review of Economic Studies, 41(2), 219-255. https://doi.org/10.2307/2296714

Williamson, O. E. (1971). The Vertical Integration of Production: Market Failure Considerations. American Economic Review, 61(2), 112-230.

Williamson, O. E. (1975). Markets and Hierarchy: Analysis and Antitrust Implications. New York: Free Press.

Williamson, O. E. (2000). The New Institutional Economics: Taking Stock, Looking Ahead. Journal of Economic Literature, XXXVIII, 595-613. https://doi.org/10.1257/jel.38.3.595

Williamson, O. E. (2009). Transaction Cost Economics: The Natural Progression. Nobel Prize Lecture.

$\mathrm{Wu}, \mathrm{Z}$. (2018). Surplus, Contractibility and Theory of the Firm. International Journal of Economic Behavior and Organization, 6(1) 1-10.

\section{Copyrights}

Copyright for this article is retained by the author(s), with first publication rights granted to the journal.

This is an open-access article distributed under the terms and conditions of the Creative Commons Attribution license (http://creativecommons.org/licenses/by/4.0/). 